
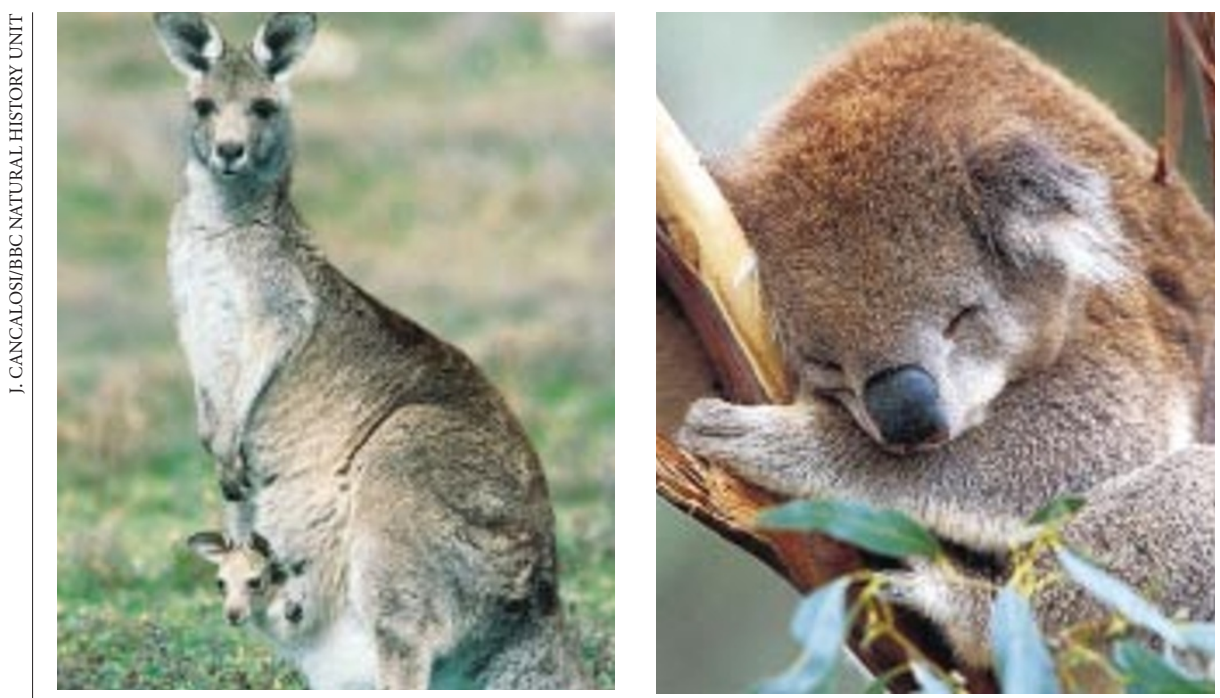

Figure 1 'Recent' and 'ancient' species of Australian marsupial. Left, Macropus giganticus, a recent species; right, Phascolarctos cinereus, an ancient species. Johnson ${ }^{2}$ has found that species of relatively recent evolutionary origin (less than 4 million years old) show a positive relationship between local abundance and geographical spread, and more ancient species a negative one. Presumably, this is because the relatives of ancient species who showed low abundances and small ranges have already become extinct.

across all species, within individual tribes (such as woodpeckers) the less recent the common ancestry they shared with other British birds the more likely the relationship was to be a positive one. The six tribes that were most distantly related to other tribes all showed positive abundance-body-size relationships.

Considerable insights can be gained into the effects of processes that operate over evolutionary timescales on contemporary ecological patterns, simply by doing separate analyses for species of different ages. Johnson's study also illustrates the power of the 'comparative method' in revealing patterns in ecological data ${ }^{10,11}$. The analyses are controlled for the non-independence of data points that results from the evolutionary relatedness of species. This at a time when the usefulness of the comparative method in ecology, rather than evolutionary biology itself, is being much debated.

The relative importance of local abundance and geographical distribution in determining risks of global extinction, and the independence of these effects, remains unknown. Johnson's analyses indicate a surprisingly simple conclusion in this regard. The slope of the lower boundary to the negative relationship between local abundance and range size for the ancient species is approximately -1 (see Fig. 2b on page 273). This implies that greater local abundance or greater range size compensate almost exactly for a reduction in the other variable. If it proves to be generally true, this will be a very significant result and might usefully simplify considerations of extinction risk.

The analyses, as reported, do not reveal whether surviving ancient species of Australian marsupials face any greater risk of extinction than the more recently evolved species. However, a higher proportion of the ancient species appear to be listed as at a significant risk of extinction in the near future, according to the current IUCN Red List of threatened animals ${ }^{12}$. This is despite the fact that the mean densities and range sizes of the ancient species are not obviously lower than those of the recent species, suggesting that age or some correlate of age may be causal (or that the likelihood of listing is biased by age or taxonomic distinctiveness). Other studies have also found that older species - or at least species in older groups - tend to be at greater risk ${ }^{13,14}$.

Having established the link between science and the search for repeated patterns, MacArthur ${ }^{1}$ continued, "many take refuge in nature's complexity as a justification to oppose any search for patterns". Along with other recent papers in the field of macroecology, that by Johnson makes the refuge seem an increasingly dull place to be.

Kevin J. Gaston is in the Department of Animal and Plant Sciences, University of Sheffield, Sheffield

S10 2TN, UK.

e-mail:k.j.gaston@sheffield.ac.uk

1. MacArthur, R. H. Geographical Ecology: Patterns in the Distribution of Species (Harper \& Row, New York, 1972).

2. Johnson, C. N. Nature 394, 272-274 (1998).

3. Hanski, I. Oikos 38, 210-221 (1982).

4. Brown, J. H. Am. Nat. 124, 255-279 (1984).

5. Gaston, K. J. Oikos 75, 211-220 (1996).

6. Walter, K. S. \& Gillett, H. J. (eds) 1997 IUCN Red List of Threatened Plants (IUCN, Gland, Switzerland, 1998).

Lawton, J. H. Trends Ecol. Evol. 8, 409-413 (1993).

8. Gaston, K. J. \& Blackburn, T. M. Proc. R. Soc. Lond. B 263, 63-68 (1996)

9. Nee, S., Read, A. F., Greenwood, J. J. D. \& Harvey, P. H. Nature 351, 312-313 (1991).

10. Rees, M. J. Ecol. 83, 891-892 (1995).

11. Harvey, P. H. J. Anim. Ecol. 65, 255-263 (1996).

12. IUCN 1996 IUCN Red List of Threatened Animals (IUCN, Gland, Switzerland, 1996).

13. Gaston, K. J. \& Blackburn, T. M. Evol. Ecol. 11, 557-565 (1997).

14. McDowall, R. M. Tuatara 17, 1-12 (1969),
Daedalus

\section{His master's fist}

Human style is a very subtle concept. Each of us has a characteristic 'house style' which shows up in everything we do. Even a Morse code operator, who can merely switch a circuit between two states, develops a personal 'fist' that can be recognized by other operators. Machines which could recognize their operator's 'fist' would be almost impossible to hijack or misuse. So Daedalus is inventing them.

The personal computer is the obvious first choice for the treatment. DREADCO's prototype has a special neural-net learning program. It accumulates its owner's keyboard 'fist', his mouse style and his characteristic pattern of usage. Soon it will recognize him very clearly. A stranger seeking to explore its files will be refused access, even if he has stolen the correct password. He will merely download a stream of abuse, together with threats that the machine will know him next time which of course it will. Meanwhile, it will still respond to its owner, even from keyboards miles away on the network.

A computer thus truly 'personalized' might even get to recognize when its owner was dead tired, or drunk, or in one of his moods again. It might refuse him access to particularly delicate files, or even tell him to go and sleep it off, and shut down.

A machine used by several people, as in a busy office, will take slightly longer to recognize them all. New employees will have to be 'inducted' by someone it has already learnt to trust. The slight initial complications will be well repaid by the subsequent improvement in security.

Cars, too, could benefit from being personalized. A car whose neural net accepted inputs from the steering wheel, accelerator, gear shift and all other movables, would soon learn the style of its driver. It would know how widely he opens the door to get in, at what speeds he changes gear, with what angular increments he corrects steering deviations, and so on. A strange hand on the wheel would at once arouse its suspicions. Further alien actions would rapidly confirm them. It would stop dead and, through the stereo speakers, shout that it was being stolen.

Now that nearly all human artefacts have a microprocessor inside them, machine recognition could spread rapidly. The bank auto-teller, the TV, the fridge, even the house front door, all could learn to greet their approved users, while snarling at attempted interlopers. The 'Haves' will be even safer from the 'Have-nots'. David Jones 